\title{
Area of lateral ventricles measured on cranial ultrasonography in preterm infants: association with outcome
}

\author{
Elie Saliba, Philippe Bertrand, Francis Gold, Sophie Marchand, Jean Laugier
}

\begin{abstract}
The association between measurements of lateral ventricle area (determined by serial ultrasound scans) and outcome was studied in 70 preterm neonates of 33 weeks' gestation or less. The study group was subdivided into four groups according to cranial ultrasonographic findings at $\mathbf{2}$ weeks postnatal age: group A $(n=15)$ had isolated periventricular/ intraventricular haemorrhage; group $B(n=20)$ had periventricular/intraventricular haemorrhage and dilated ventricles; group $C(n=24)$ had periventricular/intraventricular haemorrhage and periventricular leucomalacia with or without dilated ventricles; and group D $(n=11)$ had isolated periventricular leucomalacia. Eighty seven preterm infants with no evidence of intracranial disease and good neurodevelopmental outcomes at 2 years formed the control group. A poor outcome was observed in infants in group $B, C$, and $D$, particularly in those who had persistent dilated ventricles at 6 weeks postnatal age and extensive periventricular leucomalacia. There was no difference in outcome between group $\mathbf{A}$ and controls. During the first six weeks of life ventricular area growth velocities were significantly higher in groups B, C, D, compared with normal controls and group $A$. We suggest that persistent ventricular dilatation at this early stage carries a bad prognosis, which is the result of atrophy of the brain.
\end{abstract}

Periventricular/intraventricular haemorrhage and periventricular leucomalacia are relatively common complications in small preterm infants, ${ }^{12}$ and the most common neonatal complication of these cerebral lesions is ventricular dilatation. ${ }^{3}$ Palmer $e t$ al, and more recently Shankaran et al, have shown that infants with both periventricular/intraventricular haemorrhage and ventricular dilatation do not progress as well in their later development as infants with haemorrhage alone. ${ }^{45}$ Little is known about the natural history of ventricular dilatation after periventricular/intraventricular haemorrhage in infants who do not develop clinical posthaemorrhagic hydrocephalus, and its association with neurodevelopmental outcome.

In a previous prospective study, we reported a reference range for ventricular area size and growth velocity in preterm infants. ${ }^{6}$ The present longitudinal cranial ultrasonographic and clinical study was designed to assess (i) the growth velocity of the lateral ventricle areas during the first year of life in preterm infants who had periventricular/intraventricular haemorrhage with or without periventricular leucomalacia; (ii) the growth velocities of their head circumferences compared with the data obtained from normal controls; and (iii) whether successive measurements of ventricular area and early recognition of an increase in ventricular growth velocity are helpful in predicting neurodevelopmental outcome.

\section{Patients and methods}

Between October 1984 and July 1986, a total of 94 preterm infants of 33 weeks' gestation or less with ultrasonographic evidence of periventricular/intraventricular haemorrhage with or without periventricular leucomalacia during the neonatal period, were enrolled in a longitudinal cranial ultrasonographic and clinical study. Fifteen died in the neonatal period (haemorrhage grade IV: $n=6$, haemorrhage grade III: $n=4$, and leucomalacia: $n=5$ ). Four were lost to follow up (leucomalacia: $n=1$, haemorrhage grade II: $\mathbf{n}=1$ and haemorrhage grade I: $n=2$ ). Five infants, with cerebral malformation $(n=1)$, congenital anomalies $(n=2)$, and meningitis $(n=2)$ were excluded from the study.

The remaining 70 patients who survived for the duration of the study, were grouped according to ultrasonographic diagnosis at two weeks postnatally. Group A comprised infants with isolated periventricular/intraventricular haemorrhage alone; group B infants with periventricular/intraventricular haemorrhage and dilated ventricle but without periventricular leucomalacia; group C infants with periventricular/ intraventricular haemorrhage and leucomalacia with or without dilated ventricles; group D infants with isolated periventricular leucomalacia.

Eighty seven normal preterm infants, with no intracranial abnormalities formed the control group. The reference range for their ventricular area size and growth velocity and their neurodevelopmental outcome have been previously reported. ${ }^{6}$

\section{ULTRASOUND MEASUREMENTS}

Infants were prospectively scanned with an Advanced Technology Laboratory (Bellevue) mechanical sector scanner and $7 \cdot 5 \mathrm{MHz}$ transducer. Scanning was carried out through the anterior fontanelle in the coronal and parasagittal planes, initially within 48 hours of birth, then serially at three to four day intervals until the age of 2 weeks, and thereafter once a week or more if necessary until discharge from 
hospital. Further scans were then performed serially at 2, 4, 6, and 9 months and, if the anterior fontanelle was still open, at 12 months.

The coronal sonographic plane was used to measure the area of the lateral ventricles at the mid-body level as previously described. ${ }^{6}$ Ultrasonographic definitions and classifications, as well as diagnostic methods, remained uniform throughout the study. The severity of the haemorrhage was defined according to the four grade system of Papile et al. ${ }^{7}$ Periventricular leucomalacia was defined according to the criteria established by Fawer $e t a l,{ }^{8}$ and the sites of the changes were described separately and defined as frontal leucomalacia, occipital leucomalacia, frontoparietal leucomalacia, and frontoparieto-occipital leucomalacia in cases of extensive lesions affecting the entire periventricular white matter.

Early ventricular dilatation at two weeks postnatally was defined as the ventricular ratio of one or both lateral ventricles of greater than 0.37:1 (upper limit of normal for preterm infants) in at least two successive studies. ${ }^{9}$

Initial measurement of ventricular dilatation during the first two weeks of life was defined according to the ventricular ratio and not ventricular area, as the entire outline of the lateral ventricle is often not seen during the early stage of a periventricular/intraventricular haemorrhage particularly when a large amount of blood has filled the ventricle.

For follow up purposes the criteria we used to subdivide the babies into four groups were the maximum grade of haemorrhage or leucomalacia, and the presence or absence of ventricular dilatation at two weeks postnatally. Transient ventricular dilatation was defined as a temporary (less then six weeks) increase in size of lateral ventricles. Persistent dilatation was defined when still observed at six weeks.

\section{NEURODEVELOPMENTAL ASSESSMENT AND}

FOLLOW UP

Gestational age was determined from maternal dates and the score developed by Dubowitz et $a l .{ }^{10}$ The babies were then examined by medical staff not concerned in the neonatal care, at the ages of $4,6,9,12,18$, and 24 months. The follow up examination consisted of detailed neurological examination and an assessment of development using the Brunet-Lezine psycho- motor development scale corrected for gestational age. This test is a French adaptation of the Gesell and Amatruda scale. ${ }^{11} 12$ The items of the Brunet-Lezine test include the assessment of posture, oculomotor coordination, language, and sociability. Evaluations of vision and hearing were also made. Neurodevelopmental outcome was classified as: normal; moderate neurological abnormalities (transient abnormality of tone); developmental delay (developmental quotient of less than 80); cerebral palsy (spastic diplegia, quadriplegia, or hemiplegia); and neurosensory impairment (auditory or visual impairment). The results of the repeated neurological examinations between 18 and 24 months postnatal age were the criteria for the presence or absence of neurodevelopmental abnormalities.

\section{DATA ANALYSIS}

Postnatal growth velocity (rate of growth) of occipitofrontal circumference and ventricular area, which is the slope of growth as a linear function of time of examination for each infant, was calculated. Regressions of occipitofrontal circumference on postnatal age, and of ventricular area on postnatal age, were calculated by considering the slope for each subject and then by averaging the slopes. Linear regression analysis $(y=a x+b)$ by pooling all the data in the whole sample $(n=70)$ and in each group $(A, B$, $C$, and D), was used to evaluate the relation of ventricular area to postnatal age, of occipitofrontal circumference to postnatal age, and of ventricle area to occipitofrontal circumference.

The score on the Brunet-Lezine scale corrected for gestational age and obtained at the latest examination between 24 and 30 months of postnatal age was used for analysis. One way analysis of variance was performed on the clinical characteristics and the Brunet-Lezine scale score to test the differences between each group. Analysis of variance for repeated measurement of ventricular area and head circumference growth velocities was performed to test the differences between each group.

\section{Results}

Seventy preterm infants were studied. Their clinical details and the distribution in centiles of their weight are shown in table 1 . There were no significant differences among the four groups in

Table 1 Clinical details of the four groups studied. Values are expressed as mean (SD)

\begin{tabular}{|c|c|c|c|c|}
\hline & \multicolumn{4}{|l|}{ Group } \\
\hline & $\begin{array}{l}\text { A } \\
\text { (periventricular/ } \\
\text { intraventricular } \\
\text { haemorrhage }) \\
(n=15)\end{array}$ & $\begin{array}{l}\text { B } \\
\text { (periventricular/ } \\
\text { intraventricular } \\
\text { haemorrhage and } \\
\text { dilated ventricles }) \\
(n=20)\end{array}$ & $\begin{array}{l}\text { C } \\
\text { (periventricular/ } \\
\text { intraventricular } \\
\text { haemorrhage and } \\
\text { periventricular } \\
\text { leucomalacia }) \\
(n=24)\end{array}$ & $\begin{array}{l}D \\
\text { (periventricular } \\
\text { leucomalacia }) \\
(n=I I)\end{array}$ \\
\hline $\begin{array}{l}\text { Birth weight (g)* } \\
\text { Gestational age (weeks) } \\
\text { Apgar score at: }\end{array}$ & $\begin{array}{l}1445(350) \\
31.9(2)\end{array}$ & $\begin{array}{l}1438(288) \\
31 \cdot 5(1 \cdot 5)\end{array}$ & $\begin{array}{l}1342(307) \\
30 \cdot 3(1 \cdot 8)\end{array}$ & $\begin{array}{l}1402(327) \\
31 \cdot 2(2)\end{array}$ \\
\hline $\begin{array}{l}1 \text { minute } \\
5 \text { minutes } \\
\text { No of days ventilated }\end{array}$ & $\begin{array}{l}7(2) \\
8(2) \\
11 \cdot 87(24 \cdot 94)\end{array}$ & $\begin{array}{l}6(3) \\
7(2) \\
15 \cdot 71(20 \cdot 14)\end{array}$ & $\begin{array}{l}6(2) \\
6(2) \\
21 \cdot 8(27 \cdot 3)\end{array}$ & $\begin{array}{l}7(3) \\
8(2) \\
14 \cdot 4(21 \cdot 2)\end{array}$ \\
\hline
\end{tabular}

${ }^{*}$ Centiles of the weight $(\mathrm{g}): 5^{\circ}(900), 10^{\circ}(1000), 15^{\circ}(1050), 25^{\circ}(1200), 50^{\circ}(1400), 75^{\circ}(1660), 85^{\circ}(1740), 90^{\circ}(1800), 95^{\circ}(1850)$. 
Table 2 Main ultrasonographic diagnoses

\begin{tabular}{|c|c|c|c|c|}
\hline & \multicolumn{4}{|l|}{ Group } \\
\hline & $\begin{array}{l}\text { A } \\
\text { (periventricularl } \\
\text { intraventricular } \\
\text { haemorrhage }) \\
(n=15)\end{array}$ & $\begin{array}{l}\text { B } \\
\text { (periventricular/ } \\
\text { intraventricular } \\
\text { haemorrhage and } \\
\text { dilated ventricles) } \\
(n=20)\end{array}$ & $\begin{array}{l}C \\
\text { (periventricular/ } \\
\text { intraventricular } \\
\text { haemorrhage and } \\
\text { periventricular } \\
\text { leucomalacia) } \\
(n=24)\end{array}$ & $\begin{array}{l}D \\
\text { (periventricular } \\
\text { leucomalacia) } \\
(n=l l)\end{array}$ \\
\hline \multicolumn{5}{|c|}{ Grades of periventricular/intraventricular haemorrhage: } \\
\hline I & 8 & 7 & 10 & NA \\
\hline II & 6 & 7 & 7 & NA \\
\hline III & 1 & 6 & 6 & NA \\
\hline IV & 0 & 0 & 1 & NA \\
\hline \multicolumn{5}{|l|}{ Periventricular leucomalacia: } \\
\hline Frontal & NA & NA & 14 & 3 \\
\hline Occipital & NA & NA & 5 & 0 \\
\hline Frontal-parietal & NA & NA & 4 & 1 \\
\hline Fronto-parieto-occipital & NA & NA & 1 & 7 \\
\hline \multicolumn{5}{|l|}{ Dilated ventricles: } \\
\hline Early (two weeks) & NA & 20 & 14 & 0 \\
\hline Transient $(<$ six weeks $)$ & NA & 12 & 6 & 0 \\
\hline Persistent (<six weeks or more) & NA & 8 & 8 & 7 \\
\hline
\end{tabular}

NA, not applicable.

birth weight, gestational age, Apgar score at 1 and 5 minutes, or duration of ventilator use.

The main ultrasonographic appearances in the four groups are shown in table 2 . None of the 70 infants underwent repeat drainage of cerebrospinal fluid; in none was a shunt procedure carried out.

OCCIPITOFRONTAL CIRCUMFERENCE IN RELATION TO POSTNATAL AGE

The relation of occipitofrontal circumference to postnatal age was significant in the total group ( $\mathrm{n}=70, \mathrm{r}=0.79 ; \mathrm{p}<0.0001 ;$ occipitofrontal circumference $=0 \cdot 47$, postnatal age $=26$ weeks). There was no significant difference between the occipitofrontal circumference and postnatal age among groups $A(r=0.76$; occipitofrontal circumference $=0.48$, postnatal age $=26$ weeks), group $B(r=0.82$; occipitofrontal circumference $=0.46$, postnatal age $=27$ weeks) and normal controls $(n=87, r=0.80$; occipitofrontal circumference $=0 \cdot 44$, postnatal age $=28$ weeks). Analysis of covariance showed that the regression lines of the occipitofrontal circumference/ postnatal age association between controls and group C $(r=0.45$; occipitofrontal circumference $=0.47$, postnatal age $=25$ weeks $)$ and group $\mathrm{D}(\mathrm{r}=0.75$; occipitofrontal circumference $=0.42$, postnatal age $=25$ weeks) were parallel; there was, however, a significant difference between controls and group $C(p<0.0001)$ and between controls and group $D(p<0.0001)$.

The average of the slopes of occipitofrontal circumference for the four groups was 0.44 $(0.07) \mathrm{cm} /$ week. During the first six postnatal weeks there was no significant difference in the mean (SD) occipitofrontal circumference growth velocity (cm/week) among the four groups and normal controls: controls $=0.53(0.13)$; group $A=0.56(0.13)$; group $B=0.56(0.21)$; group $\mathrm{C}=0.53(0.10)$; and group D $0.50(0.11)$.

\section{VENTRICULAR AREA IN RELATION TO}

POSTNATAL AGE

The relation of ventricular area to postnatal age was highly significant among the four groups $(n=70, r=0.45 ; p<0.0001$; ventricular area $=$
0.95 , postnatal age $=6.6$ weeks). When group A and normal controls were compared (analysis of covariance), there was no significant difference in the ventricular area and postnatal age association. There was, however, a significant increase in ventricle size in relation to postnatal age in groups B, C, and D compared with both normal controls and group A $(p<0.0001$, analysis of covariance between groups $\mathrm{B}, \mathrm{C}, \mathrm{D}$, and controls). Except for group A and controls, the regression lines of the ventricular area and postnatal age association were not parallel (fig 1).

The average of the slopes of ventricular area for the four groups during the first six postnatal weeks was $0.85(1.02) \mathrm{mm}^{2} /$ week.

The mean ventricular growth velocity $\left(\mathrm{mm}^{2} /\right.$ week) during the first six postnatal weeks in each group is shown in table 3 . There was no

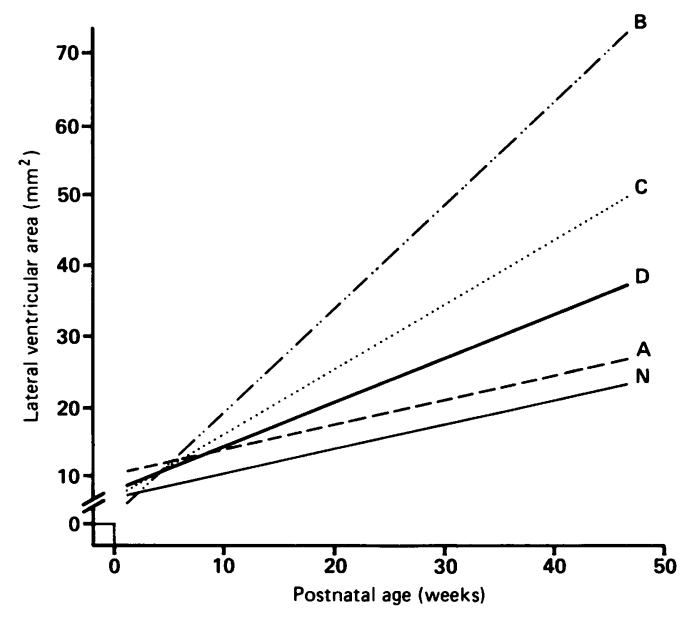

Figure 1 Regression lines of the area of the lateral ventricles during the postnatal period in the four groups compared with normal controls. $N=$ normal controls $(n=87, r=0.52$, $p<0.0001$, ventricular area $0.38 \mathrm{~mm}^{2}$, postnatal age $=7$ weeks); $A=$ periventricular/intraventricular haemorrhage $\left(n=15, r=0.32, p<0.0001\right.$, ventricular area $=0.38 \mathrm{~mm}^{2}$, postnatal age $=10$ weeks); $B=$ periventricular/intraventricular hostmorrhage and dilated ventricles $(n=20, r=0.58$, haemorrhage and dilated ventricles $(n=20, r=0 \cdot 58$,
$p<0 \cdot 0001$, ventricular area $=1.53 \mathrm{~mm}^{2}$, postnatal age $=5$ weeks); $C=$ periventricular/intraventricular haemorrhage and periventricular leucomalacia $(n=24, r=0.43, p<0.0001$, ventricular area $=0.96 \mathrm{~mm}^{2}$, postnatal age $=7$ weeks); and $D=$ periventricular leucomalacia $(n=11, r=0.26, p<0.01$, ventricular area $=0.66 \mathrm{~mm}^{2}$, postnatal age $=8$ weeks). 
Table 3 Ventricular area growth velocity $\left(\mathrm{mm}^{2} /\right.$ week $)$ during the first six postnatal weeks. Values are expressed as mean (SD)

\begin{tabular}{|c|c|c|c|c|}
\hline \multicolumn{5}{|l|}{ Group } \\
\hline $\begin{array}{l}\text { Controls } \\
(n=87)\end{array}$ & $\begin{array}{l}\text { A } \\
\text { (periventricular/ } \\
\text { intraventricular } \\
\text { haemorrhage }) \\
(n=15)\end{array}$ & $\begin{array}{l}\text { B } \\
\text { (periventricular/ } \\
\text { intraventricular } \\
\text { haemorrhage and } \\
\text { dilated ventricles) } \\
(n=20)\end{array}$ & $\begin{array}{l}C \\
\text { (periventricular/ } \\
\text { intraventricular } \\
\text { haemorrhage and } \\
\text { intraventricular } \\
\text { leucomalacia) } \\
(n=24)\end{array}$ & $\begin{array}{l}D \\
\text { (periventricular } \\
\text { leucomalacia) } \\
(n=I I)\end{array}$ \\
\hline \multirow{2}{*}{$0.39(0 \cdot 19)$} & $0.32(0.3)$ & $1.85(1.07)$ & $0.90(0.45)$ & $0.78(0.64)$ \\
\hline & NS & & & \\
\hline \multicolumn{2}{|r|}{$\mathrm{p}<0.0001$} & 1 & & \\
\hline \multicolumn{3}{|c|}{$p<0.0004$} & & \\
\hline \multicolumn{4}{|c|}{$\mathrm{p}<0.0005$} & \\
\hline
\end{tabular}

NS, not significant.

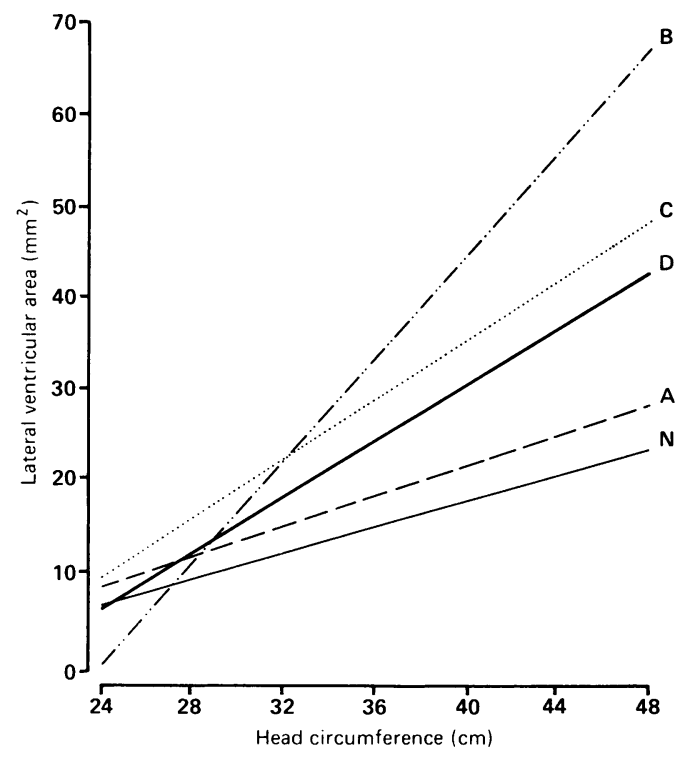

Figure 2 Regression lines of the area of the ventricles and head circumference in the four groups compared with normal controls. $N=$ normal controls $(n=87, r=0 \cdot 54, p<0 \cdot 0001$, ventricular area $=0.72 \mathrm{~mm}^{2}$, occipitofrontal circumference $=$ $11 \mathrm{~cm}) ; A=$ periventricular/intraventricular haemorrhage $\left(n=15, r=0.45, p<0.0001\right.$, ventricular area $=0.85 \mathrm{~mm}^{2}$, occipitofrontal circumference $=12 \mathrm{~cm}) ; B=$ periventricular $/$ intraventricular haemorrhage $(n=20, r=0.61, p<0.0001$, ventricular area $=2 \cdot 8 \mathrm{~mm}^{2}$, occipitofrontal circumference $=$ $66 \mathrm{~cm}) ; C=$ periventricular/intraventricular haemorrhage and periventricular leucomalacia $(n=24, r=0.45, p<0.0001$, ventricular area $=1.67 \mathrm{~mm}^{2}$, occipitofrontal circumference $=$ $31 \mathrm{~cm}) ;$ and $D=$ periventricular leucomalacia $(n=11$, $r=0.36, p<0 \cdot 0007$, ventricular area $=1.54 \mathrm{~mm}^{2}$, occipitofrontal circumference $=21 \mathrm{~cm}$ ).

significant difference in the ventricular area growth velocity between group $\mathrm{A}$ and normal controls. The ventricular area growth velocity was significantly higher in groups $\mathrm{B}, \mathrm{C}, \mathrm{D}$, compared with normal controls and group $\mathrm{A}$.
VENTRICULAR AREA IN RELATION TO

OCCIPITOFRONTAL CIRCUMFERENCE

Figure 2 shows the regression lines drawn for each group compared with that for normal controls. Infants in group A and normal controls had a similar ventricular area/occipitofrontal circumference association. Infants in group B had a significant $(p<0.0001)$ increase in ventricular area/occipitofrontal circumference association compared with controls. Infants in groups $C$ and $D$ had a higher ventricular area/occipitofrontal circumference association compared with normal controls and group A $(\mathrm{p}<0.0001)$.

\section{NEURODEVELOPMENTAL OUTCOME}

Infants in group A did as well as normal controls. Infants in group B had a less good outcome: of the eight infants with persistent dilated ventricles at six weeks of life, seven had a development quotient $<80$, one had reduced visual activity. Poor outcomes were observed in infants in group C, particularly in the eight infants who also had persistent dilated ventricles; all those infants had development quotients $<80$. Of the two infants who developed cerebral palsy, one had extensive periventricular leucomalacia. Infants in group D had the worst outcome: of the seven infants with extensive lesions and persistent dilated ventricles, four developed cerebral palsy (table 4).

Perinatal factors such as gestational age, birth weight, Apgar score, number of days requiring ventilation, and neurological examination at discharge, did not relate significantly to outcome. Neurodevelopmental outcome related principally to two factors, namely persistent dilated ventricles at 6 weeks $(p<0.001)$, and the presence of extensive periventricular leucomalacia $(\mathrm{p}<0.005)$, particularly if they were bilateral.

Figure 3 shows the distribution of ventricular

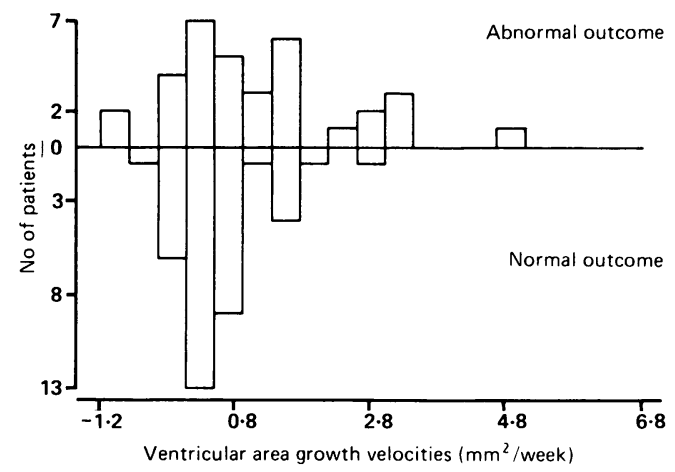

Figure 3 Ventricular growth velocities in relation to the neurodevelopmental outcome. Abnormal outcome $(n=34)=$ developmental quotient $<80$, and normal outcome $(n=36)=$ developmental quotient 80 or more.

Table 4 Neurological and developmental outcome of the four groups studied

\begin{tabular}{|c|c|c|c|c|}
\hline & \multicolumn{4}{|l|}{ Group } \\
\hline & $\begin{array}{l}\text { A } \\
\text { (periventricular/ } \\
\text { intraventricular } \\
\text { haemorrhage }) \\
(n=15)\end{array}$ & $\begin{array}{l}\text { B } \\
\text { (periventricular/ } \\
\text { intraventricular } \\
\text { haemorrhage and } \\
\text { dilated ventricles }) \\
(n=20)\end{array}$ & $\begin{array}{l}\text { C } \\
\text { (periventricular) } \\
\text { intraventricular } \\
\text { haemorrhage and } \\
\text { intraventricular } \\
\text { leucomalacia) } \\
(n=24)\end{array}$ & $\begin{array}{l}D \\
\text { (periventricular } \\
\text { leucomalacia) } \\
(n=11)\end{array}$ \\
\hline $\begin{array}{l}\text { No with developmental delay } \\
\text { (developmental quotient }<80 \text { ) }\end{array}$ & 4 & 9 & 13 & 8 \\
\hline $\begin{array}{l}\text { No with moderate neurological } \\
\text { abnormalities } \\
\text { No with neurosensorial impairment } \\
\text { No with cerebral palsy }\end{array}$ & $\begin{array}{l}1 \\
1 \\
0\end{array}$ & $\begin{array}{l}4 \\
4 \\
0\end{array}$ & $\begin{array}{l}7 \\
3 \\
2\end{array}$ & $\begin{array}{l}5 \\
5 \\
4\end{array}$ \\
\hline
\end{tabular}


area growth velocities for the first six weeks in relation to the neurodevelopmental outcome.

\section{Discussion}

Infants in group A did not differ significantly from normal controls, though they kept slightly higher values of ventricular area throughout the study. In a cranial ultrasonographic study, Graziani et al showed that the width of the lateral ventricles and brain hemispheres in a group of preterm infants with periventricular/intraventricular haemorrhage without early ventricular dilatation did not differ significantly from those of preterm infants without evidence of haemorrhage. ${ }^{13}$ D'Souza et al have shown that infants with haemorrhage alone had a similar ventricle width to biparietal diameter ratio compared with normal controls. ${ }^{14}$ The favourable outcome observed in this group is in agreement with similar results reported by others. ${ }^{5-13}$

Dilated ventricles usually occur in infants who have sustained moderate to severe haemorrhage, and may be related to posthaemorrhagic obstruction. Both Palmer et al and Stewart et al, however, have occasionally noted ventricular dilatation after small haemorrhages in the subependymal area and within the ventricles. ${ }^{4} 5$ 7-15 Others have also described porencephalic atrophy resulting from haemorrhages in preterm infants. ${ }^{16}$

Dilated ventricles occurred even after small or moderate haemorrhage (group B). In infants with persistent dilatation, ventricular area remained significantly greater than in normal controls. There was no significant increase in cranial growth velocity despite the persistent increase of ventricular area. Although clinical signs and rapidly enlarging head circumference may be delayed or absent in small preterm babies with haemorrhage, the rate of growth of the occipitofrontal circumference in infants with posthaemorrhagic hydrocephalus in the absence of cerebral atrophy should be as great, if not greater, than that of infants without haemorrhage. Our results suggest therefore that posthaemorrhagic hydrocephalus alone is an insufficient explanation for dilated ventricles in some infants. Whether progressive brain atrophy is taking place or a decrease in early cranial growth related to the neonatal illness is occurring is not certain. Infants in group B with persistent dilated ventricles may have included those with brain atrophy as a result of diffuse hypoxic-ischaemic parenchymal damage not detected by ultrasonographic scanning, and subsequently associated with retarded development. Volpe et al have shown by positron emission tomography that periventricular infarction can be more extensive than the haemorrhage. ${ }^{16}$

In the 24 infants in group $C$ and the 11 infants in group $\mathrm{D}$, ventricular area growth velocity was significantly greater than that of normal controls; in addition, the rate of growth of occipitofrontal circumference remained significantly lower throughout the study, particularly in those with extensive lesions, suggesting diffuse cerebra atrophy with retarded development and cerebral palsy.

None of the infants with persistent dilated ventricles required shunts. In a recent study, Shankaran et al showed that the lack of ventricular decompression after ventriculoperitoneal shunt was strongly associated with poor outcome, suggesting that cerebral atrophy may have occurred before the insertion of the shunt in some infants with posthaemorrhagic ventricular dilatation. ${ }^{5}$
Early recognition of ventricular dilatation is important, as it seems to correlated with neurodevelopmental outcome. We chose to evaluate ventricular size quantitatively, because when ventricular dilatation occurs linear measurements do not reflect this change. Horbar et al, suggested that the lateral ventricular cross sectional area should be measured when dilatation occurred. ${ }^{17}$ This was done in one infant with posthaemorrhagic hydrocephalus by planimetry of multiple coronal sections.

In our study, although the overlap among the groups is important, early determination of ventricular area growth velocities seems to be discriminatory for assessing outcome. The relatively increased value of the SDs of the slopes of the ventricular area growth velocity, is explained by the fact that some infants (group B) had rapid posthaemorrhagic ventricular dilatation.

We conclude that longitudinal cranial ultrasonographic follow up provides a useful assessment of brain in preterm infants. Comparison of direct ultrasound measurements (ventricular area) in the detection of changing ventricular size is helpful in planning treatment and in defining the relationship between neurodevelopmental outcome and cerebral lesions.

We thank Professor Malcolm Levene for his advice and critical review of the manuscript. The study was supported by grant

1 Thorburn RJ, Lipscombe AP, Stewart AL, et al. Prediction of death and major handicap in very preterm infants by brain ultrasound. Lancet 1981;ii:1119-21.

2 Levene MI, Fawer CL, Lamont RF. Risk factors in the development of intraventricular haemorrhage in the preterm neonate. Arch Dis Child 1982;57:410-7.

3 Ahmann PA, Lazzara A, Dykes FD, et al. Intraventricular haemorrhage in the high-risk preterm infant: incidence and haemorrhage in the high-risk preterm

4 Palmer P, Dubowitz LMS, Levene MI, et al. Developmental and neurological progress of preterm infants with intraventricular haemorrhage and ventricular dilatation. Arch Dis Child 1982;57:748-52.

5 Shankaran S, Koepke T, Woldt E, et al. Outcome after posthaemorrhagic ventriculomegaly in comparison with mild haemorrhage without ventriculomegaly. 7 Pediatr 1989;110:109-14

6 Saliba E, Bertrand P, Gold F, Valant MC, Laugier J. Area of lateral ventricles measured on cranial ultrasonography in preterm infants: reference range. Arch Dis Child 1990;65: 1029-32.

7 Papile LA, Brustein J, Brustein R, et al. Incidence and evolution of subependymal and intraventricular haemorrhage: a study of infants with birth weights less than 1500 gm. $¥$ Pediatr 1978;92:529-34.

8 Fawer CL, Calame A, Perentes E, et al. Periventricular leukomalacia: a correlation study between real-time ultrasound and autopsy findings. Neuroradiology 1985;27: sound and

9 Johnson ML, Jack LA, Rumack CM, et al. B-mode echoencephalography in the normal and high risk infant. $A \mathcal{F} R$ 1979;133:375-81.

10 Dubowitz LMS, Dubowitz V, Goldberg C. Clinical assessment of gestational age in the newborn infant. $\mathcal{f}$ Pediatr 1970;77:1-10.

11 Brunet $\mathrm{O}$, Lezine I. Echelle de développement psychomoteur de la première enfance. Le développement psychologique de la première enfance. Paris: PUF, 1976:11-34.

12 Gesell A, Amatruda C. Developmental diagnosis. New York: Hoeber, 1947.

13 Graziani LJ, Pasto M, Stanley C, et al. Cranial ultrasound and clinical studies in preterm infants. 7 Pediatr 1985;106: 269-76.

14 D'Souza SW, Gowland M, Richard SB, et al. Head size, brain growth and lateral ventricles in very low birthweight growth and lateral ventricles in very

15 Stewart AL, Thorburn RJ, Hope PL, et al. Developmental and neurological progress of preterm infants with intraand neurological progress of preterm infants with intraDis Child 1982;57:748-52.

16 Volpe JJ, Herscovitch P, Perlman JM, et al. Positron emission tomography in the newborn: extensive impair ment of regional cerebral blood flow with intraventricular ment of regional cerebral blood flow with intraventricular Pediatrics 1983;72:589-601.

17 Horbar JD, Walters CL, Philip AG, Lucey JF. Ultrasound detection of changing ventricular size in posthemorrhagic hydrocephalus. Pediatrics 1980;66:674-8. 